\title{
Effects after the lockdown on emergency room admissions for psychiatric evaluation: An observational study from the province of Forli-Cesena, Italy
}

\author{
Massimiliano Beghi, ${ }^{1}$ Riccardo Brandolini, ${ }^{2}$ Laura Biondi, ${ }^{3,4}$ Claudia Corsini, ${ }^{3}$ Carlo Fraticelli, ${ }^{5}$ \\ Rosa Sant'Angelo, ${ }^{1}$ Giovanni De Paoli ${ }^{1}$ \\ ${ }^{1}$ Department of Mental Health and Pathological Dependencies, AUSL Romagna, Cesena; ${ }^{2}$ Department of \\ Mental Health and Pathological Dependencies, AUSL Romagna, Rimini; ${ }^{3}$ Department of Mental Health and \\ Pathological Dependencies, AUSL Romagna, Ravenna; ${ }^{4}$ Department of Biomedical and NeuroMotor \\ Sciences, Psychiatry Unit, Alma Mater Studiorum, Bologna; ${ }^{5}$ Department of Mental Health and Addictions, \\ ASST Lariana, Como, Italy
}

\begin{abstract}
The aim was to study the number of accesses to the Emergency Room (ER) requiring psychiatric evaluation in the four months following the lockdown period for the COVID-19 outbreak (May $4^{\text {th }}$, 2020 -August $31^{\text {th }}, 2020$ ). The study is a retrospective longitudinal observational study of the ER admissions of the Hospitals of Cesena and Forlì (Emilia Romagna region) leading to psychiatric
\end{abstract}

Correspondence: Massimiliano Beghi, Department of Mental Health, AUSL Romagna, Piazzale Giommi, 47521, Cesena, Italy.

Tel.: +390547352702, +390547646294

E-mail: massibeghi@libero.it

Key words: Pandemic; follow-up; outbreak; COVID-19; mental health.

Acknowledgements: We would like to thank Eleonora Monti for her important contribution in data collection and Dr. Elisa Bianchi for statistical analysis.

Contributions: MB: study design, data collection, manuscript preparation; RB: data collection, revision of the literature; LB: data collection, revision of the literature; CC: manuscript preparation; CF: manuscript preparation; RSA: manuscript preparation; GDP: study design.

Conflict of interest: The authors declare no conflict of interest.

Availability of data and materials: All data generated or analyzed during this study are included in this published article.

Ethics approval and consent to participate: The Ethics Committee of Romagna (CEROM) approved this study (Prot. 3069/2021). The study is conformed to the Helsinki Declaration of 1964, as revised in 2013, concerning human and animal rights.

Informed consent: According to the ethic committee (CEROM) Written informed consent was not required, since all the data were collected anonymously to allow statistical elaboration and were managed in aggregate form to avoid patients' identification.

Received for publication: 23 April 2021.

Revision received: 16 August 2021.

Accepted for publication: 16 August 2021.

This work is licensed under a Creative Commons Attribution 4.0 License (by-nc 4.0).

(C) Copyright: the Author(s), 2021

Licensee PAGEPress, Italy

Emergency Care Journal 2021; 17:9827

doi:10.4081/ecj.2021.9827 assessment. Sociodemographic variables, history for medical comorbidities or psychiatric disorders, reason for ER admission, psychiatric diagnosis at discharge and measures taken by the psychiatrist were collected. An increase of $9.4 \%$ of psychiatric assessments was observed. The difference was more pronounced in the first two months after lockdown, with a $21.7 \%$ increase of number of ER accesses, while after two months numbers were the same as those of the year before. Admission with anxiety symptoms and history of psychiatric disorder decreased significantly. Moreover, there is an age trend with an increasing age of admission.

\section{Introduction}

Between March $9^{\text {th }}$ and May $3^{\text {rd }} 2020$, the Italian Government imposed a national lockdown, restricting the movements of the population except for certified needs such as work and health circumstances, the temporary closure of non-essential services, productive activities and businesses, in response to the growing pandemic of COVID-19 in the country. After this phase, the Italian Government decided to ease the lockdown restricting measures, and people who had been at home during the lockdown returned to their workplaces and were also allowed to visit relatives and other loved ones.

The WHO declared the novel COVID-19 disease a pandemic, with severe consequences for health and global economic activity and Italy is one of the hardest hit countries. ${ }^{1}$ A recent systematic review of the literature ${ }^{2}$ has underlined the negative psychological effects of quarantine, such as the development of Post-Traumatic Stress Disorder (PTSD) symptoms, like confusion and anger. Stressful factors during quarantine were identified, including quarantine length $>10$ days, fear to contract the infection, boredom and frustration for not doing daily-life activities, lack of basic elements of food, water, clothes, that could be extended to the following months. ${ }^{2}$

After lockdown, the financial loss as a result of lockdown created serious socioeconomic distress and was found to be the main risk factor for symptoms of psychological disorders and both anger and anxiety several months after lockdown. ${ }^{2}$

Access to the Emergency Room (ER) is considered an index of severe psychiatric distress, since it underlines a compelling request due to patient's discomfort. Recent reports from Italy, France, Germany, and Portugal, found a decrease of psychiatric ER visits ${ }^{3-}$ ${ }^{6}$ during the lockdown.

However, data on psychiatric distress after the lockdown are still scarce. Data from the United Kingdom ${ }^{7}$ show a longer-term urgent or emergency mental health referrals acceleration after an instantaneous drop at the beginning of the lockdown. 
The aim of our study was to compare the number of accesses to the ER requiring psychiatric evaluation in the province of ForlìCesena in the region Emilia-Romagna, North-Eastern Italy, in the four months following the "phase one" of the restrictions for the COVID-19 outbreak (from May $4^{\text {th }}, 2020$ to August 31 th 2020 ) with those of the same period of the year 2019, and also to investigate the socio-demographic and clinical characteristics of patients admitted.

\section{Materials and Methods}

The study is a retrospective longitudinal observational study of the ER admissions of the Hospitals of Cesena and Forlì leading to psychiatric assessment. The catchment area included 333,112 adult inhabitants, distributed as follows: Cesena, 176,232; Forlì, 156,884

\section{Measures}

The electronic databases were searched for of following data: sociodemographic variables (age, gender, ethnicity, marital status, housing status), positive history for medical comorbidities or psychiatric disorders, reason for ER admission, psychiatric diagnosis at discharge and measures taken by the caring psychiatrist (hospitalization in psychiatric ward, other).

The study was approved by the local ethics committee on March $19^{\text {th }}, 2021$. A consent form was not required, since all the data were collected anonymously to allow statistical elaboration and were managed in aggregate form to avoid patients' identification.

\section{Statistical Analysis}

All relevant variables were included in a general database and analyzed by using the SPSS 16.0 software. Basic descriptive statistics were performed, with continuous variables presented as absolute Numbers $(\mathrm{N})$, mean, Standard Deviation (SD) and categorical variables as frequencies and percentages.

The sample was divided into two groups: variables related to post lockdown period (May $4^{\text {th }}, 2020$-August $31^{\text {th }}, 2020$ ) and variables related to the control period (May $4^{\text {th }}, 2020$-August $31^{\text {th }}$, 2019).

The association between each variable and the period was tested using the chi-square. All variables found to be statistically significant in univariate analyses and with a missing rate $<20 \%$ were included in a multivariable binary logistic regression model. Results are reported as Odds Ratios (OR) with 95\% confidence intervals $(95 \% \mathrm{CI})$. The significance level was set at $5 \%$.

\section{Results}

Considering the whole period, an increase of $9.4 \%$ of psychiatric assessments was observed $(p=0.16)$. The difference was thus significant in the first two months after lockdown $(\mathrm{p}=0.04)$, with a $21.7 \%$ increase of number of ER accesses (Table 1), while after two months numbers were the same as those of the year before.

\section{Comparison between post-quarantine period and cor- responding antecedent period}

Table 1 displays the comparison of variables referring to the two time periods, outlining some statistically significant changes. In the multivariate logistic regression model, only admission with anxiety symptoms (OR:0.53 CI: 0.36-0.80) and history of psychi- atric disorder (OR:0.52 CI:0.32-0.85) decreased significantly. Moreover, there is an age trend with an increasing age of admission and a significant reduction in people aged $<30$ years (OR: 0.64 CI:0.42-0.98).

\section{Discussion}

In the light of our results there has been a slight increase in number of ER admissions, after the lockdown, compared to those of the previous year, especially in people who had not a positive psychiatric history. Our results, even if lower than expected considering findings of the systematic review ${ }^{2}$ and than previous data, ${ }^{7}$ point out the psychological discomfort due to the pandemic, the social restrictions during and following lockdown, and the subsequent economic burden, especially in males. The discrepancy with the current literature could be explained in part by the decree approved by the Italian Government in support to workers and their families blocked the collective terminations; this could have postponed the consequences of the economic burden of the pandemic and lowered the psychological discomfort, since the loss of a job is a predictor of social distress. A study carried out in Lombardy during the economic crisis ${ }^{8}$ found that the subjects who lost their permanent employment were $17 \%$ more likely to receive psychotropic drug prescriptions than the controls, but the difference was significant only for males. This discomfort is in line with the current literature ${ }^{9,10}$ and could be justified by the higher number of admissions for suicide ideation/self-harm/suicide attempt, even if our findings did not attain statistically significance due to the small numbers.

This increase was significant only in the first two months after quarantine, while after that period the numbers aligned to those of the previous year. In our opinion, there has been a sort of rebound effect just after the lockdown, when fragmentation symptoms, that found their place in the 'outside world' during lockdown, come back in the inside world, resulting in discomfort with a consequent worsening of psychotic and mood symptoms. ${ }^{11}$ By contrast, there was a significant decrease in people referring to the ER for anxiety symptoms, in line with data during lockdown from the same area ${ }^{3}$ and with those of previous reports, that reported a gradual decrease in anxiety symptoms..$^{9,10,12-14}$ These data are in contrast with a survey from a large Italian sample that found a $17.6 \%$ of patients experiencing anxiety symptoms and $41.6 \%(\mathrm{~N}=8,619)$ reporting to feel at least moderately stressed by the situation. ${ }^{15}$ The fear of COVID-19 contagion could influence people with anxiety symptoms, since hospitals were by far places at highest risk of contact. They tried to avoid an admission using different strategies as atneed therapies and contacts with the outpatient clinics. The increasing age of people referring to the ER is in line with previous data, but only among younger individuals. ${ }^{7}$

Our data are not surprising: it is known that the consequences of the pandemic are more severe in people aged 65+ years both in terms of death (about 8/10 deaths) and intensive care admissions. ${ }^{16}$ The fear for the pandemic could thus induce or worsen a psychiatric disorder. Moreover, old people have a reduced perception of their life and physical health, and they usually suffer also from comorbid conditions requiring follow-up visits and on-going assistance: the loss of social networks may create a situation in which mental health and psychosocial support needs of many older people are no longer met. For the millions of older people who live in care facilities, physical distancing measures (that restrict visitors and group activities) persisting after the lockdown, can negatively affect their well-being and, consequently, their mental health. 
Table 1. General characteristics of the sample during lockdown and, for comparison, during a corresponding period in 2019.

\begin{tabular}{|c|c|c|c|c|c|}
\hline \multirow[t]{2}{*}{ Variable } & \multicolumn{2}{|c|}{ post- lockdown } & \multicolumn{2}{|c|}{2019 control period } & \multirow[t]{2}{*}{ Significance (p) } \\
\hline & $\mathbf{N}$ & $\%$ & $\mathbf{N}$ & $\%$ & \\
\hline Age range (years) & & & & & $\mathrm{p}=0.003$ \\
\hline$<31$ & 115 & 23.1 & 148 & 32.5 & \\
\hline $31-45$ & 133 & 26.7 & 112 & 24.6 & \\
\hline $46-65$ & 152 & 30.5 & 136 & 29.8 & \\
\hline$>65$ & 98 & 19.7 & 60 & 13.2 & \\
\hline Gender & & & & & $\mathrm{p}=0.363$ \\
\hline Male & 262 & 50.7 & 226 & 49.6 & \\
\hline Female & 237 & 47.5 & 230 & 50.4 & \\
\hline Marital status & & & & & $\mathrm{p}=0.048$ \\
\hline Single & 230 & 52 & 233 & 59.6 & \\
\hline Married/cohabitant & 125 & 28.3 & 105 & 26.9 & \\
\hline Divorced & 63 & 14.3 & 34 & 8.7 & \\
\hline Widowed & 24 & 5.4 & 19 & 4.9 & \\
\hline Ethnicity & & & & & $\mathrm{p}=0.192$ \\
\hline Italian & 422 & 84.7 & 372 & 81.6 & \\
\hline Foreign & 76 & 15.3 & 84 & 18.4 & \\
\hline Occupation & & & & 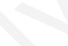 & $\mathrm{p}=0.003$ \\
\hline Current worker & 125 & 29.6 & 113 & 31.8 & \\
\hline Retired & 99 & 23.4 & 46 & 13 & \\
\hline Socially inactive (student, housewife, disabled) & 70 & 16.5 & 66 & 18.6 & \\
\hline Unemployed & 129 & 30.5 & 130 & 36.6 & \\
\hline Housing status & & & & & $\mathrm{p}=0.776$ \\
\hline Alone & 79 & 17.1 & 62 & 14.5 & \\
\hline Family of origin & 158 & 34.3 & 146 & 34.1 & \\
\hline Acquired family & 140 & 30.4 & 131 & 30.6 & \\
\hline Therapeutic center & 66 & 14.3 & 65 & 15.2 & \\
\hline Homeless & 5 & 1.1 & 6 & 1.4 & \\
\hline Other & 13 & 2.8 & 18 & 4.2 & \\
\hline Comorbidity & & & & & $\mathrm{p}=0.033$ \\
\hline No & 280 & 64.8 & 284 & 71.7 & \\
\hline Yes & 152 & 35.2 & 112 & 28.3 & \\
\hline History of psychiatric disorders & & & & & $\mathrm{p}=0.019$ \\
\hline No & 91 & 18.2 & 58 & 12.7 & \\
\hline Yes & 408 & 81.8 & 398 & 87.3 & \\
\hline In psychiatric care & & & & & $0=0.350$ \\
\hline Current & 295 & 59.1 & 289 & 63.3 & \\
\hline Past & 86 & 17.2 & 75 & 16.4 & \\
\hline Never & 118 & 23.6 & 92 & 20.2 & \\
\hline Reason for ER admission & & & & & $\mathrm{p}=0.007$ \\
\hline Suicide ideation/self-harm/ suicide attempt & 65 & 13.0 & 44 & 9.6 & \\
\hline Psychomotor agitation/intoxication/confusion & 181 & 36.3 & 148 & 32.5 & \\
\hline Psychotic episode & 64 & 12.8 & 43 & 9.4 & \\
\hline Mood symptoms & 79 & 15.8 & 77 & 16.9 & \\
\hline Anxiety symptoms & 110 & 22.0 & 144 & 31.6 & \\
\hline Psychiatric diagnosis & & & & & $\mathrm{p}=0.362$ \\
\hline Psycho-organic disorder & 24 & 5.3 & 37 & 7.4 & \\
\hline Psychotic disorder & 65 & 14.3 & 79 & 15.9 & \\
\hline Mood disorder & 84 & 18.5 & 110 & 22.1 & \\
\hline Anxiety disorder & 38 & 8.4 & 38 & 7.6 & \\
\hline Personality disorder & 48 & 10.5 & 31 & 6.2 & \\
\hline Intellectual disability & 18 & 4 & 26 & 5.2 & \\
\hline Addiction disorder & 31 & 6.4 & 37 & 5.8 & \\
\hline Adjustment disorder & 51 & 11.2 & 51 & 10.3 & \\
\hline Axis I/Axis II diagnosis & 14 & 3.1 & 13 & 2.6 & \\
\hline Dual diagnosis & 82 & 18 & 81 & 16.3 & \\
\hline Measure taken by the psychiatrist & & & & & $\mathrm{p}=0.030$ \\
\hline No measure, drug prescription & 112 & 24.6 & 125 & 25.1 & \\
\hline Send to the outpatient & 212 & 46.6 & 203 & 40.7 & \\
\hline Psychiatric ward admission & 95 & 20.9 & 142 & 28.5 & \\
\hline Other measure (e.g. other ward admission) & 36 & 7.9 & 29 & 5.8 & \\
\hline
\end{tabular}


Lastly, older people have always suffered from the lack of structural training and work policies, the precariousness or the protections necessary for carrying out the same. The data on employment, in fact, emphasize how accesses of people socially/working inactive, are high in both periods, defining the work as a determinant of health.

\section{Limitations}

Our study has several limitations. First, the retrospective design could have led to biases in the collection of some variables. Second, we focused on psychiatric visits: in some cases, the same patient may have more than one admission and this could lead to an overestimation of some demographic variables. Third, due to the fact that ER database does not provide diagnoses following international classifications, such as ICD, we used descriptive psychiatric diagnoses formulated by the clinician, following clinical evaluation and using natural language. Finally, the study was performed in a local setting and, hence, generalizability of our findings may be limited.

\section{Conclusions}

There has been a mild increase in number of ER admissions, after the lockdown, compared to those of the previous year, especially in people who had not a positive psychiatric history. Further studies in larger populations are needed to confirm data from our sample. Moreover, studies carried when collective terminations will be unblocked could give us the real economic burden of the pandemic and the psychiatric consequences.

\section{References}

1. Nurchis MC, Pascucci D, Sapienza M, et al. Impact of the Burden of COVID-19 in Italy: Results of Disability-Adjusted Life Years (DALYs) and Productivity Loss. Int J Environ Res Public Health 2020;17:4233.

2. Brooks SK, Webster RK, Smith LE, et al. The psychological impact of quarantine and how to reduce it: rapid review of the evidence. Lancet 2020;395:912-20.

3. Beghi M, Brandolini R, Casolaro I, et al. Effects of lockdown on emergency room admissions for psychiatric evaluation: an observational study from the AUSL Romagna, Italy. Int J Psychiatry Clin Pract 2020;21:1-5.

4. Pignon B, Gourevitch R, Tebeka S, et al. Dramatic reduction of psychiatric emergency consultations during lockdown linked to COVID-19 in Paris and suburbs. Psychiatry Clin Neurosci 2020;74:557-9.

5. Hoyer C, Ebert A, Szabo K, et al. Decreased utilization of mental health emergency service during the COVID-19 pandemic. Eur Arch Psychiatry Clin Neurosci 2021;271:377-9.

6. Gonçalves-Pinho M, Mota P, Ribeiro J, et al. The impact of COVID-19 pandemic on psychiatric emergency department visits - A descriptive study. Psychiatr Q 2020;25:1-11.

7. Chen S, She R, Qin P, et al. The medium-term impact of COVID-19 lockdown on referrals to secondary care mental health services: A controlled interrupted time series study. Front Psychiatry 2020;11:585915.

8. Cornaggia CM, Beghi M, Mezzanzanica M, et al. Psychotropic drug consumption and employment status in time of economic crisis (2007-2011). Psychiatr Q 2017;88:371-84.

9. O'Connor RC, Wetherall K, Cleare S, et al. Mental health and well-being during the COVID-19 pandemic: longitudinal analyses of adults in the UK COVID-19 Mental Health \& Wellbeing study. Br J Psychiarty 2020;1-8.

10. Killgore WDS, Cloonan SA, Taylor EC, et al. Trends in suicidal ideation over the first three months of COVID-19 lockdowns. Psychiatry Res 2020;293:113390.

11. Gabbard GO. Psychodynamic psychiatry in clinical practice, 3rd edition. Washington DC: American Psychiatry Press, 2000.

12. Fancourt D, Steptoe A, Bu F. Trajectories of anxiety and depressive symptoms during enforced isolation due to COVID-19 in England: a longitudinal observational study. Lancet Psychiatry 2020;8:141-9.

13. Gijzen M, Shields-Zeeman L, Kleinjan M, et al. The bittersweet effects of COVID-19 on mental health: Results of an online survey among a sample of the dutch population five weeks after relaxation of lockdown restrictions. Int J Environ Res Public Health 2020;17:9073.

14. González-Sanguino C, Ausín B, Castellanos MA, et al. Mental health consequences of the Covid-19 outbreak in Spain. A longitudinal study of the alarm situation and return to the new normality. Prog Neuropsychopharmacol Biol Psychiatry 2020;107:110219.

15. Fiorillo A, Sampogna G, Giallonardo V, et al. Effects of the lockdown on the mental health of the general population during the COVID-19 pandemic in Italy: Results from the COMET collaborative network. Eur Psychiatry 2020;63:e87.

16. Ritchie H, Mathieu E, Rodés-Guirao L, et al. Coronavirus Pandemic (COVID-19). Our World in Data; 2020. Available from: https://ourworldindata.org/coronavirus 